\title{
Mud Cake Removing to Improve the Well Cementing Quality
}

\author{
Jianwei Zhang ${ }^{1, a^{*}, \text { Jian Wang }}{ }^{2, b}$, Qingming Meng ${ }^{3, c}$, Xin Li $^{4, d}$, Baodong Zhu ${ }^{5, e}$ \\ 1,2,3,4,5 Provincial Key Laboratory of Oil and Gas Chemical Technology, College of Chemistry and \\ Chemical Engineering, Northeast Petroleum University, Daqing, Heilongjiang, China \\ abenbenbao@163.com, ${ }^{b}$ mrwj@nepu.edu.cn, ' qingmingmeng@163.com, ${ }^{d} 1429885592 @ q q . c o m$, \\ ebaodongzhu@126.com
}

Keywords: oil-based drilling fluid; mud cake; cementing strength; well cementation

Abstract: This In order to improve the oil well cementing interface strength, the removing agent (JCJ) and cleaning agent $(\mathrm{QXJ})$ were used from the perspective of clearing the mud cake on the borehole wall and wellbore casing. The factors influencing the effect of JCJ and QXJ were researched through metal plate immersion test, cleaning test and cementing strength simulation experiments. The results showed that the removal rate of mud cake could reach to $88 \%$ when the metal plate was first soaked in the drilling fluid at $55^{\circ} \mathrm{C}$ for 40 min when $1 \%$ (weight) of JCJ was added into the drilling fluid and then was cleaned in the aqueous solutions within $1 \% \mathrm{JCJ}$ at $45^{\circ} \mathrm{C}$ for $25 \mathrm{~min}$. The cementing strength simulation experiments showed that the cementing strengths of the interfaces between the cement and the wellbore casing (the first interface), the cement and the borehole wall (the second interface) could be enhanced to 10.3 and 8 times respectively which indicated the well cementing quality could be improved effectively. Besides, the main properties of drilling fluid did not changed greatly after adding JCJ into the drilling fluid.

\section{Introduction}

The developments in ultra deep oil well, horizontal oil well and water-sensitive strata become more and more widely with the oil exploitation ${ }^{[1,2]}$. In well drilling the oil-based drilling fluid is popular because of its excellent lubricity, strong rejection capability, good stability, high-temperature resistance, etc ${ }^{[3-5]}$. Using the oil-based drilling fluid could increase the drilling speed and improve drilling quality but some problems also appear one of which is the shear strengths between the cement and the wellbore casing or the borehole wall decrease greatly because of the mud cake of oil-based drilling fluid on the wellbore casing and borehole wall ${ }^{[6,7]}$. This kind of mud cake could not be removed by cleaning additives used in water-based drilling fluid. So it is important to research a new method to resolve the above problem. In order to decrease the amount of drilling fluid adhering on the wellbore casing and borehole wall and improve the cementing quality the removing agent (JCJ) and cleaning agent $(\mathrm{QXJ})$ were studied in this paper.

\section{Experimental}

Materials The drilling fluid and well cement were obtained from Daqing Drilling Company of China National Petroleum Corporation (CNPC) . The removing agent (JCJ) was a non-ionic surface active agent, and the cleaning agent $(\mathrm{QXJ})$ was alcohols mixture.

Metal plate immersion test The effect of JCJ was tested by the metal plate immersion test. The less residue of the oil-based drilling fluid on the metal plate, the better removing effect of JCJ. In the test, the metal plate $(70 \mathrm{~mm} \times 50 \mathrm{~mm} \times 1 \mathrm{~mm})$ was first immersed in the JCJ-containing drilling fluid at constant temperature for a period of time, and then the mud cake formed on the plate, the plate with mud cake was taken out and weighed. The weight-growth of the metal plate defined as the difference of its weight before and after impregnation was used to evaluate the effect of JCJ. The lower the weight difference of the plate, the better the effect of LPP.

Cleaning test In order to improve the removing effect further the cleaning test was carried out. After the metal plate immersion test the metal plate with drilling fluid was then cleaned in the aqueous 
solutions within $1 \% \mathrm{JCJ}$, some time later the metal plate was taken out and weighed. Also the weight-growth of the metal plate was used to evaluate the effect of QXJ.

Cementing strength simulation test Both the steel sleeve and the cylindrical core were immersed in a drilling fluid with at $45{ }^{\circ} \mathrm{C}$ with $1 \%$ JCJ under normal pressure, 24 hours later, when the mud cakes formed on the wall, the steel sleeve and the core were removed from the drilling fluid and cleaned in the aqueous solutions within $1 \%$ QXJ at $55{ }^{\circ} \mathrm{C}$ for 30 min to get rid of the dummy cake. After that, they were placed in the center of mould and fixed. Cement slurry was poured into the annular space between the steel sleeve and the core and the mould. The mould filled with cement slurry was put at room temperature for $24 \mathrm{~h}$, when the cement surface was solidified, the mould was put into a oven at $45^{\circ} \mathrm{C}$ for 7 days. The cementing strengths in the interface were measured by a CMT5105 tension tester (USA).

Measuring of he rheological properties of the oil-based drilling fluid Adding JCJ into the drilling fluid, and the mixture was stirred at $4000 \mathrm{rpm}$ for $15 \mathrm{~min}$ in blender. The rheological parameters of the drilling fluid were measured by ZNN-D6B six-speed rotational viscometer respectively, that is all made in China. These tests were carried out repeatedly but with the different amounts of JCJ.

Instrumental Analyses The typical samples in the interface were chosen and analyzed by scanning electron microscopy (SEM) that was performed by the thermal field emission SEM analyzer ( $I$ IGMA ,German ZEISS) in the high vacuum mode.

\section{Results and discussion}

The Influence of dosage on the effect of JCJ Changing the JCJ dosage in the drilling fluid and measuring the removal rate of mud cake. The result was shown in figure 1 . It could be seen that the removal rate of mud cake was increased from $44 \%$ to $79 \%$ when the dosage increased from $0.5 \%$ to $1 \%$ but when the dosage was lager than $1 \%$ it was changed not obviously. So the proper JCJ dosage could be chose as $1 \%$.

The Influence of temperature on the effect of JCJ Figure 2 shows the influence of temperature on the effect of JCJ that was concluded by the metal plate immersion test with $1 \%$ JCJ adding into the drilling fluid and 40min soaking time. Clearly, the removal rate of mud cake was improved first and then weakened when the temperature was increased from $25^{\circ} \mathrm{C}$ to $85^{\circ} \mathrm{C}$. The maximum removal rate of mud cake was occurred at $55^{\circ} \mathrm{C}$ which was $79 \%$. But between $25^{\circ} \mathrm{C}$ to $85^{\circ} \mathrm{C}$, the largest removal rate of mud cake change was only $14 \%$ showing the effect of JCJ was less influenced by the temperature and could be used in most of process of well drilling.

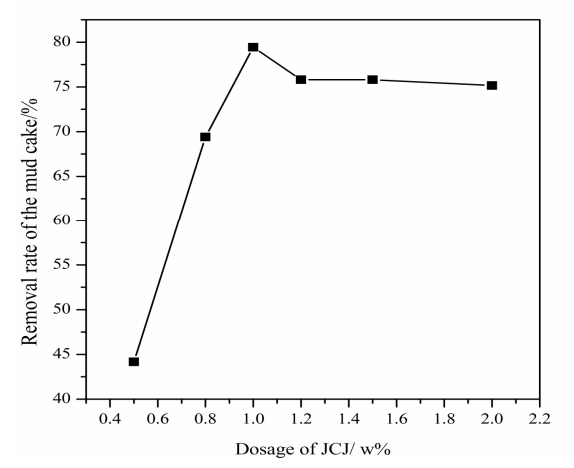

Fig.1 Influence of JCJ dosage on the removal rate of mud cake

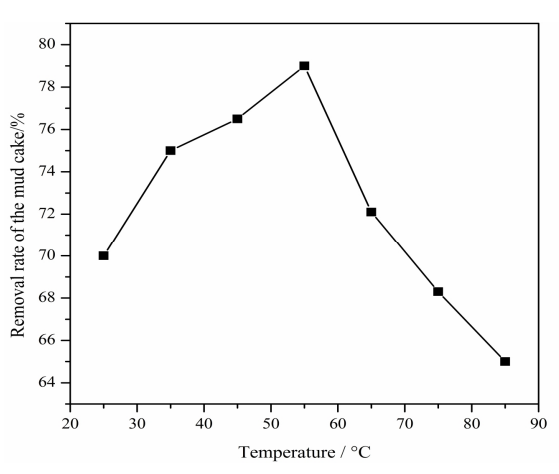

Fig. 2 Influence of soaking temperature on the removal rate of mud cake

The Influence of soaking time on the effect of JCJ Figure 3 shows the influence of soaking time on the effect of JCJ that was concluded by the metal plate immersion test with $1 \% \mathrm{JCJ}$ adding into the drilling fluid at $55^{\circ} \mathrm{C}$. It could be seen that the removal rate of mud cake was increased from $74 \%$ to $80 \%$ when the soaking time was lower than $40 \mathrm{~min}$ but after $40 \mathrm{~min}$ it was nearly unchanged. Thus we 
could conclude that JCJ could removing the mud cake on the metal plate effectively within short time that was conducive to reduce the time of cleaning the mud cake before well cementing.

The Influence of dosage on the effect of QXJ In order to reduce the mud cake thickness, the metal plate soaked in the drilling fluid with $1 \%$ JCJ was cleaned in the aqueous solutions within different dosage of QXJ, and the influence of dosage on the effect of QXJ was shown in figure 4. It could be seen that the removal rate of mud cake was increased from $79 \%$ to $83 \%$ when the dosage increased from $0 \%$ to $3 \%$ but when the dosage was lager than $1 \%$ it was changed not obviously in fig. 4 . So the proper QXJ dosage could be chose as $1 \%$.

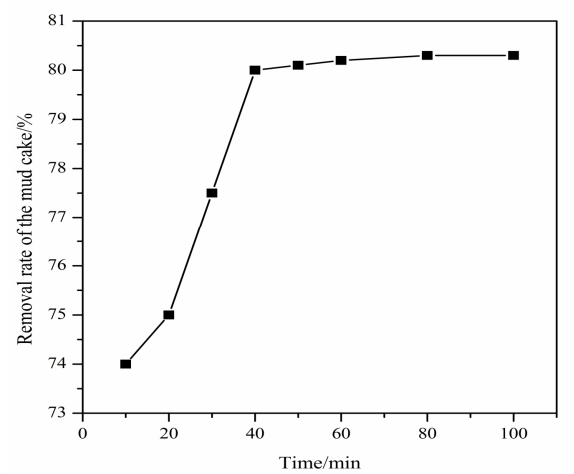

Fig. 3 Influence of soaking time on the removal rate of mud cake

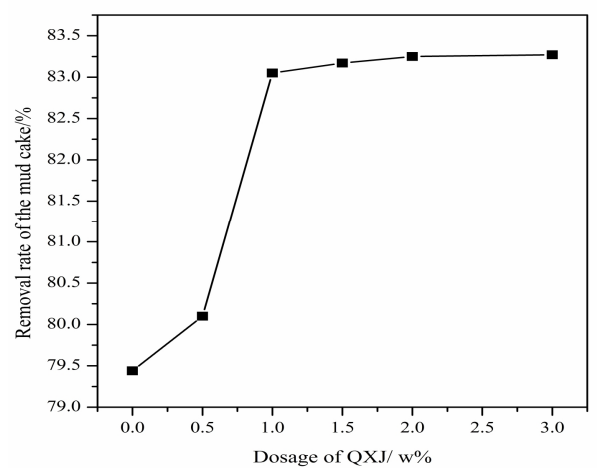

Fig. 4 Influence of QXJ dosage on the removal rate of mud cake

The Influence of cleaning temperature on the effect of QXJ In order to reduce the mud cake thickness, the metal plate soaked in the drilling fluid with $1 \%$ JCJ was cleaned in the aqueous solutions within $1 \% \mathrm{JCJ}$, and the influence of temperature on the effect of QXJ was shown in figure 5. Clearly, it could be seen that the removal rate of mud cake was increased from $80 \%$ to $89 \%$ when the temperature was changed from $25^{\circ} \mathrm{C}$ to $45^{\circ} \mathrm{C}$. But when the temperature increased to $75^{\circ} \mathrm{C}$ the removal rate of mud cake changed less obviously, nearly kept $89 \%$. From the above the effect of QXJ was influenced by the temperature. When the temperature was more than $45^{\circ} \mathrm{C}$ it could achieve the best cleaning effect which was the working temperature range of the oil-based drilling fluid.

The Influence of cleaning time on the effect of QXJ Figure 6 shows the influence of cleaning time on the effect of QXJ that the cleaning temperature was $45^{\circ} \mathrm{C}$. We could see that the removal rate of mud cake was improved with the cleaning time increasing, but when the cleaning time was larger than $25 \mathrm{~min}$ it kept about $89 \%$. Thus we could conclude the effect of QXJ was influenced by the cleaning time but it could achieve the best cleaning effect only $25 \mathrm{~min}$ later that improved QXJ could play a role effectively in a short time.

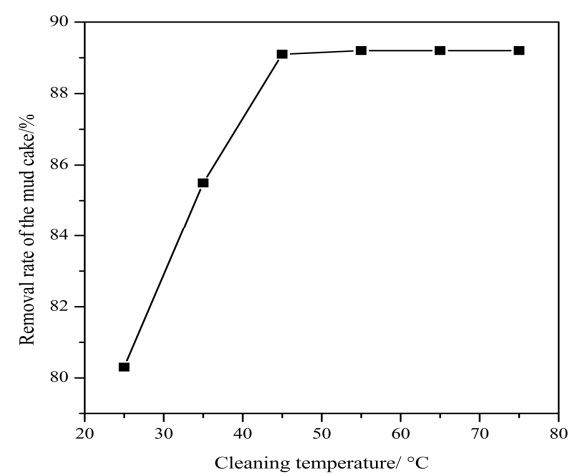

Fig. 5 Influence of cleaning temperature on the removal rate of mud cake

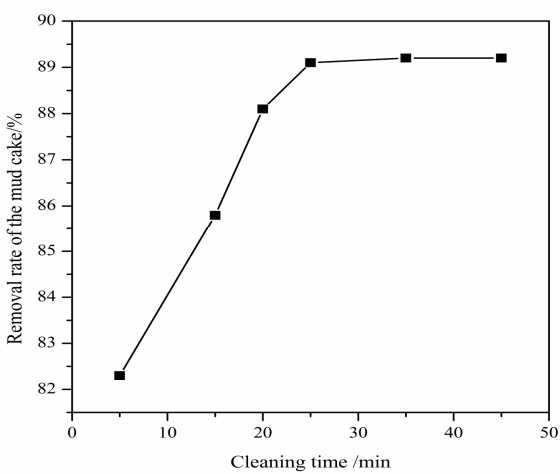

Fig. 6 Influence of cleaning time on the removal rate of mud cake

The influence of JCJ on rheological properties of the oil-based drilling fluid A series of oil-based drilling fluid formations with different contents of JCJ were prepared, and the fluid properties 
including apparent viscosity (AV), plastic viscosity (PV) and yield point (YP) were measured. The results are listed in Table 1.

Table 1 Rheological behaviors of oil-based drilling fluid with different contents of JCJ

\begin{tabular}{cccccc}
\hline Fluid formulation & $\begin{array}{c}\boldsymbol{A} \boldsymbol{V} \\
(\mathbf{m P a} \cdot \mathbf{s})\end{array}$ & $\begin{array}{c}\boldsymbol{P V} \\
(\mathbf{m P a} \cdot \mathbf{s})\end{array}$ & $\boldsymbol{Y P / P a}$ & $\boldsymbol{Y P} / \boldsymbol{P V}$ & $\boldsymbol{n}$ \\
\hline Oil-based fluid (1) & 80.5 & 69.0 & 21.0 & 0.30 & 0.7 \\
(1) $+0.2 \%$ JCJ & 79.5 & 68.7 & 20.3 & 0.30 & 0.7 \\
(1)+0.4\% JCJ & 79.2 & 67.0 & 19.1 & 0.29 & 0.7 \\
(1)+0.6\% JCJ & 79.0 & 66.2 & 18.2 & 0.27 & 0.7 \\
(1) $+0.8 \%$ JCJ & 78.8 & 64.5 & 17.5 & 0.27 & 0.7 \\
(1)+1.0\% JCJ & 78.5 & 62.0 & 16.9 & 0.27 & 0.7 \\
(1)+1.2\% JCJ & 78.2 & 60.5 & 15.2 & 0.25 & 0.7 \\
\hline All data were measured at $45 \pm 0.5^{\circ} \mathrm{C}$.
\end{tabular}

Clearly, with the addition of the JCJ into the drilling fluid, the rheological parameters including AV, $\mathrm{PV}, \mathrm{YP}$ and YP/PV decreased, but rheological behavior index basically did not change compared with the original drilling fluid. These results indicate that the JCJ is effective at improving the rheological properties of the oil-based drilling fluid, but does not greatly affect the rheological properties.

Test of cementing strength in the interface Cementing strength simulation test was carried out and the cementing strengths in the interfaces were measured by a tension tester (Table 2). The cementing strength is the value that the maximum press force divides by the area of cementing interface.

Table 2 Cementing strengths at the interfaces of well cementation

\begin{tabular}{cccccc}
\hline Interface & $\begin{array}{c}\text { Dosage of JCJ } \\
(\mathbf{w \% )}\end{array}$ & $\begin{array}{c}\text { Dosage of QXJ } \\
\mathbf{( w \% )}\end{array}$ & $\begin{array}{c}\text { Area of cementing } \\
\text { interface }\left(\mathbf{c m}^{\mathbf{2}}\right)\end{array}$ & $\begin{array}{c}\text { Maximum } \\
\text { press force } \\
(\mathbf{k N})\end{array}$ & $\begin{array}{c}\text { Cementing } \\
\text { strength } \\
(\mathbf{M P a})\end{array}$ \\
\hline First & 0 & 0 & 180 & 6.28 & 0.35 \\
interface & 1 & 1 & 183 & 66.55 & 3.70 \\
\hline Second & 0 & 0 & 106 & 7.71 & 0.73 \\
interface & 1 & 1 & 107 & 61.42 & 5.74 \\
\hline
\end{tabular}

Clearly, the cementing strengths of the first and second interfaces of well cementation were raised 9.6 and 7 times, respectively, which proved adding JCJ into the drilling fluid first and then cleaning the steel sleeve and the core adhering drilling fluid with QXJ aqueous solutions could improve the cementing strength effectively.

SEM analysis Finally, to investigate the effect of JCJ and QXJ on the cement-formation bonding, SEM analysis was performed. The obtained results of SEM analysis showed in figure 7, in which a was the sample treated by JCJ and QXJ and b was the sample not treated by JCJ and QXJ. Compared fig.7a and $7 \mathrm{~b}$, it can be concluded that the hydrated rodlike gels of aluminium silicates could be found in the sample at the cementing-formation interface that was treated by JCJ and QXJ. JCJ and QXJ in the cementing strength simulation test could remove most of the drilling fluid adhering on the wellbore casing and the borehole wall, leading to a greater degree of contact between the cement wellbore casing or the borehole wall, so the interface strength could be increased.
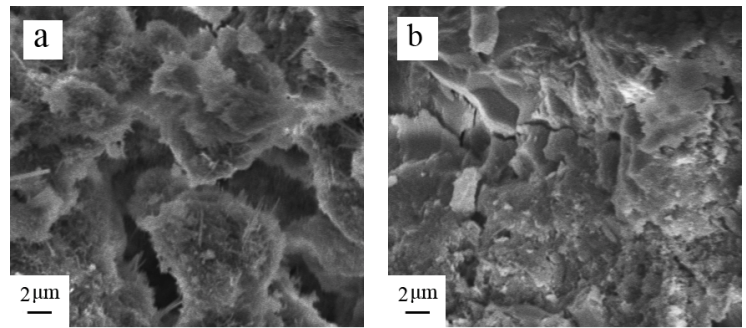

Fig. 7 SEM images of samples at the cement-formation interface

\section{Conclusions}

The removing agent (JCJ) and cleaning agent $(\mathrm{QXJ})$ were used in order to improve the oil well cementing interface strength and the proper conditions have been investigated and the following conclusions are derived. Adding $1 \%$ JCJ into the oil-based drilling fluid at $55^{\circ} \mathrm{C}$ could reduce the 
drilling fluid quantity adhering on the metal plate and the further cleaning in $1 \%$ QXJ-containing aqueous solutions at $45^{\circ} \mathrm{C}$ for 25 min could result in the high removal rate of mud cake which was $89 \%$. Besides the cementing strength simulation experiments showed that the cementing strengths of the interfaces between the cement and the wellbore casing (the first interface), the cement and the borehole wall (the second interface) could be enhanced to 10.6 and 8 times after using JCJ and QXJ, which indicated JCJ and QXJ could improve the well cementing quality greatly and the method in this paper was feasible.

\section{References}

[1] S.D. Zhu, J.F. Wei, Z.Q. Bai, G.S. Zhou, J. Miao, R. Cai, Failure analysis of P110 tubing string in the ultra-deep oil well, Engineering Failure Analysis. 18(2011) 950-962.

[2] Xuezhong Wang, Jinzhu Wang, Mingquan Qiao, Horizontal well, nitrogen and viscosity reducer assisted steam huff and puff technology: Taking super heavy oil in shallow and thin beds, Chunfeng Oilfield, Junggar Basin, NW China, as an example, Petroleum Exploration and Development. 40(2013) 104-110.

[3] J. Hermoso, F. Martinez-Boza, C. Gallegos, Influence of viscosity modifier nature and concentration on the viscous flow behaviour of oil-based drilling fluids at high pressure, Applied Clay Science. 87 (2014) 14-21.

[4] L. Skallia, J.S. Buckleya, Y. Zhangb, N.R. Morrowb, Surface and core wetting effects of surfactants in oil-based drilling fluids, Journal of Petroleum Science and Engineering. 52(2006) 253-260.

[5] Fulong Ning, Ling Zhang, Yunzhong Tu, Guosheng Jiang, Maoyong Shi, Gas-hydrate formation, agglomeration and inhibition in oil-based drilling fluids for deep-water drilling, Journal of Natural Gas Chemistry. 19(2010) 234-240.

[6] Shishir Shivharea, Ergun Kurub, A study of the pore-blocking ability and formation damage characteristics of oil-based colloidal gas aphron drilling fluid s, Journal of Petroleum Science and Engineering. 122(2014) 257-265.

[7] Tan Nguyen, Stefan Miska, Mengjiao Yu, Nicholas Takach, Experimental study of dynamic barite sag in oil-based drilling fluids using a modified rotational viscometer and a flow loop, Journal of Petroleum Science and Engineering . 78(2011) 160-165. 